\title{
Incorporating herbivorous sea urchins in ramet culture of staghorn coral Acropora cervicornis
}

\author{
J. E. Serafy ${ }^{1,2, *}$, P. Gillette ${ }^{2}$, M. W. Miller ${ }^{1}$, D. Lirman², T. R. Capo ${ }^{2}$ \\ ${ }^{1}$ National Marine Fisheries Service, Southeast Fisheries Science Center, 75 Virginia Beach Drive, Miami, Florida 33149, USA \\ ${ }^{2}$ University of Miami, Rosenstiel School of Marine and Atmospheric Science, 4600 Rickenbacker Causeway, Miami, \\ Florida 33149, USA
}

\begin{abstract}
Since the 2006 listing of the staghorn coral Acropora cervicornis as threatened under the US Endangered Species Act, interest has increased in its culture for laboratory studies, restoration and ex situ conservation efforts. A pervasive problem in coral culture is substrate overgrowth by algae and other spatial competitors. We conducted a laboratory study to examine the utility of introducing herbivores, juvenile variegated sea urchins Lytechinus variegatus, to tanks containing small $\left(<1 \mathrm{~cm}^{2}\right)$ A. cervicornis ramets. Growth of coral ramets on ceramic tile substrates was monitored in recirculating seawater tanks over $210 \mathrm{~d}$ and measured in terms of area change under 3 treatment conditions: (1) presence of laboratory-reared, juvenile, variegated sea urchins; (2) weekly scraping of algal turfs from the tile substrate by means of a razor blade; and (3) absence of both urchins and manual turf removal (i.e. control). Over the course of the study, coral area decreased in the control treatment, but increased in the scraped and urchin-containing treatments. All 3 treatments differed significantly from one another, with the highest growth rate $\left(3.1 \mathrm{~mm}^{2} \mathrm{~d}^{-1}\right)$ associated with the manual removal of algal competitors, followed by the urchin $\left(1.9 \mathrm{~mm}^{2} \mathrm{~d}^{-1}\right)$ and control treatments $\left(-0.8 \mathrm{~mm}^{2} \mathrm{~d}^{-1}\right)$. Given the relative ease of $L$. variegatus culture, the incorporation of variegated sea urchins in the coral ramet production process appears to provide at least a partial substitute for manual algal removal. Although coral growth in the presence of urchins was slower than with manual removal, human labor costs associated with the latter may out-weigh any production rate improvements in large-scale operations.
\end{abstract}

KEY WORDS: Sea urchin $\cdot$ Coral production $\cdot$ Lytechinus $\cdot$ Algae control Resale or republication not permitted without written consent of the publisher

\section{INTRODUCTION}

Reef-building corals are the foundation of the most biodiverse ecosystems on the planet, providing myriad valuable and irreplaceable ecosystem services. By virtue of their large spatial extent, high structural complexity and connectivity with seagrass, mangrove and pelagic systems, coral reefs provide, among other services, shoreline protection, tourism, fisheries, and aesthetic and cultural value. However, over the past 3 decades, reef-building corals around the globe have experienced significant declines. This is particularly evident in the Caribbean region where live coral cover fell from ca. 50 to ca. $10 \%$ between the late 1970s and the early 2000s (Gardner et al. 2003), and catastrophic events impact coral reefs regularly (e.g. Hughes et al. 2003, Miller et al. 2009). Subsequent and dramatic declines in fish abundances (Paddack et al. 2009) and a reduction in the structural complexity of Caribbean reefs (Alvarez-Filip et al. 2009) have also been reported in region-wide metaanalyses. This region is home to the first corals listed under the US Endangered Species Act (Acropora cervicornis Lamarck, 1816 and A. palmata Lamarck, 1816). While these losses to populations, habitat quality, ecosystem resilience and services are widely 
recognized, little consensus exists as to the type and sequence of management actions that would protect these resources, as considerable management and conservation effort over the past 2 decades have largely failed to stem declines. The lack of agreement among researchers derives from the lack of understanding of basic coral biology/health, disease etiology and the relative contributions (and synergies) of such stresses as toxins, elevated nutrient levels, overfishing, exotic species, ocean acidification and temperature extremes. This situation hinders the development of effective management actions.

Although in situ monitoring of coral reefs is essential for documenting their status and trends, field observations alone are inadequate for discerning the influence of the many possible factors driving coral decline, especially when evidence suggests that the importance of those factors differs among species and locations. Coral researchers have conducted simple laboratory investigations on Caribbean corals to increase understanding of basic coral physiology, especially patterns of settlement and growth, since at least the early 1900s (e.g. Mayer 1914). However, controlled, replicated studies using corals of consistent size, morphology, environmental history and genotype (i.e. a 'white mouse') are increasingly recognized as necessary for understanding, and ultimately mitigating, the myriad threats facing coral reefs (Rinkevich \& Shafir 1998, Woodley et al. 2003, Shafir et al. 2006, Riebesell et al. 2010). Interest in laboratory studies, restoration and ex situ conservation efforts specifically targeting Acopora cervicornis has increased since the 2006 listing of this species as threatened under the US Endangered Species Act.

While the stressors affecting coral populations can differ widely at the local level, competition with macroalgae and algal turfs has been recognized as a global cause of coral mortality (McCook et al. 2001, Diaz-Pulido \& McCook 2004, Birrell et al. 2008, DiazPulido et al. 2009, Barott et al. 2012) and as a determinant of coral recovery from climatic disturbances (Wilson et al. 2012). In fact, recent studies on the effectiveness of Marine Protected Areas have identified the preservation of an intact and diverse herbivore guild as one of the keys to enhancing coral resilience (Hughes et al. 2007, Mumby et al. 2007, Mumby \& Steneck 2008). The impacts of coral-algal competition can be especially intense for small corals that can be easily overgrown by faster-growing algae in both natural and experimental settings (Lirman 2001, Yap \& Alvarez Molina 2003, Calfo 2007). The algal overgrowth problem has prompted examination of the alga-grazing gastropod mollusc Trochus niloticus as a potential means of enhancing coral recruitment in the field. For example, Omori et al. (2006) found that coral recruitment was significantly enhanced on $T$. niloticus aquaculture structures off Japan. However, deliberate introduction of T. niloticus on artificial reef substrates off the Philippines was unsuccessful in terms of algal removal and coral recruitment due to predation on the gastropods (Villanueva et al. 2010).

In this study, we tested the use of juvenile variegated sea urchins Lytechinus variegatus Lamarck, 1816 as a tool for preventing algal turf competition and overgrowth of small coral ramets of the staghorn coral Acropora cervicornis within a controlled, ex situ culture setting. The present paper reports on a $210 \mathrm{~d}$ laboratory study comparing the growth rates of $A$. cervicornis ramets under 3 treatments: (1) presence of $L$. variegatus juveniles, (2) weekly manual removal of algal turfs by means of a razor blade (scraping) and (3) absence of both urchins and manual alga removal (i.e. control).

\section{MATERIALS AND METHODS}

\section{Animal sources and preparation}

The Acropora cervicornis ramets used in this study were derived from coral samples obtained from a nearshore reef off Broward County, Florida, USA $\left(26^{\circ} 09.138 \mathrm{~N}, 80^{\circ} 05.537 \mathrm{~W}\right)$, in April 2006. After a $5 \mathrm{~d}$ acclimation period, the broodstock coral was fragmented and mounted on $5 \times 5 \mathrm{~cm}$ ceramic tiles, which were held in the semi-recirculating culture system described in the following subsection. These corals were kept in culture at the facility for approximately 6 yr before the start of the current experiment. Ramets were produced from these cultured fragments by using a $10 \mathrm{~mm}$ biopsy punch (AcuPunch) to excise circular pieces of coral tissue (approximately 10 polyps) with underlying skeleton from thin areas of lateral encrusting growth over the square tile substrate. Next, each circular coral piece was attached to a $5 \times 5 \mathrm{~cm}$ ceramic tile using cyanoacrylate gel. Once in place, the mounted ramets were allowed to recover for a period of $14 \mathrm{~d}$ before the start of the trial. Only ramets with a solid, uniform attachment to the ceramic substrate were used in the trials; these were subsequently labeled and randomly assigned to the 3 experimental treatments of this study.

The juvenile Lytechinus variegatus used in the urchin treatment were cultured at the University of 
Miami Experimental Hatchery from broodstock urchins collected from seagrass beds off Key Biscayne, Florida. These adults were induced to spawn by injection of $1 \mathrm{ml}$ of $0.5 \mathrm{M} \mathrm{KCl}$ (George et al. 2004, Buitrago et al. 2005). Subsequent larval culture followed the roller-bottle culture procedures set forth in Capo et al. (2009). Briefly, larvae were held in 2.41 roller bottles and fed a diet of Isochrysis galbana Parke, 1949 and Chaetoceros muelleri subsalsum Johansen and Rushforth, 1985 for approximately $14 \mathrm{~d}$. Once developmentally competent (presence of rudiment and pedicellaria), metamorphosis was induced using a benthic diatom film. Post-metamorphic animals grew to the juvenile stage with a diet of cultured macroalgae (e.g. Ulva sp. and Gracilaria ferox J. Agardh, 1852) (Capo et al. 1999) prior to use in the experimental treatment.

\section{Experimental set-up}

Coral growth trials were conducted in the semirecirculating coral culture system contained in a $183 \times 51 \times 25 \mathrm{~cm}$ fiberglass trough. Targeted study duration was 6 mo. Water used in the system was thermally regulated seawater that was sterilized using ultraviolet light (UV), passed through a protein skimmer and mechanically filtered using a $10 \mu \mathrm{m}$ canister filter. Recirculating water was continuously supplemented at a rate of $1 \mathrm{l} \mathrm{h}^{-1}$ with $1 \mu \mathrm{m}$ filtered, UV-treated seawater pumped directly from the ocean. Artificial light (14 h light:10 h dark cycle) was provided with banks of $175 \mathrm{~W}, 10000 \mathrm{~K}$ Ushio metal halide bulbs, delivering an approximate illumination of $280 \mu \mathrm{mol} \mathrm{m}{ }^{-2} \mathrm{~s}^{-1}$ at the water's surface. Water quality (temperature, salinity, $\mathrm{pH}$, dissolved oxygen) was monitored hourly throughout the trial for the recirculating system with a YSI 5200 multi-probe meter.

Groups of 3 coral ramets were randomly assigned among 9 clear, uncovered polycarbonate bins $(24 \times$ $24 \times 20 \mathrm{~cm})$, and these were randomly assigned among 3 treatments: urchins, scraped and control. Water circulation within each bin was provided with a submersible Hydor Koralia $908 \mathrm{l} \mathrm{h}^{-1}$ pump, with incoming seawater entering each bin at a rate of $21 \mathrm{~min}^{-1}$, resulting in complete water turnover in each bin every $6 \mathrm{~min}$. This rapid turnover ensured all experimental bins were exposed to the same water quality conditions. The urchin-addition treatment included 4 Lytechinus variegatus, with initial test diameters (TD) of approximately $1 \mathrm{~cm}$. Using small urchins among the ramets reduced the possibility of mechanical damage from urchin grazing (Forsman et al. 2006). Approximately every $7 \mathrm{~d}$, bins were replaced with clean ones, and the position of the bins within the system and the corals within bins were randomly varied over the course of the study. All coral ramets were fed weekly with a mixture of Zeigler larval fish and shrimp diet (Larval AP100) and Cyclopeze frozen copepods. Every $7 \mathrm{~d}$, the tile surfaces surrounding the ramets in the manual algal removal treatment were scraped using a razor blade until no algal biomass was evident with the naked eye. Care was taken not to damage the coral growing margin with the razor blade, and scraped turf was discarded. Corals in the control treatment were left undisturbed throughout.

\section{Coral growth measurement and analysis}

Coral growth in this experiment was primarily lateral; branch formation was not observed. Hence, projected area occupied by each ramet was monitored via digital still photography on Days 0, 15, 29, $42,71,84,98,140,182$ and 210; a ruler was placed within each image for scale. The digital images were subsequently analyzed to generate area estimates $\left(\mathrm{mm}^{2}\right)$ for each ramet at each time interval using the US National Institutes of Health software package Image J. Treatment effects on coral growth (area) were evaluated via repeated-measures analysis using SAS (1990) statistics software. To avoid the problem of pseudo-replication (Hurlbert 1984), analysis was performed such that the dependent variable was the sum of coral area for each replicate bin as opposed to using individual ramet areas within bins. Treatment-specific growth rates were estimated and compared using a general linear model (i.e. PROC GENMOD) within the SAS (1990) software whereby (1) time (day), treatment and the interaction term were the independent variables and (2) each bin was treated as a 'subject' measured over time. Differences among growth rates were evaluated via post hoc $t$-tests. Statistical significance was declared at the $\mathrm{p}<0.05$ level.

\section{RESULTS}

A summary of hourly water quality conditions over the $210 \mathrm{~d}$ trial is provided in Table 1 . The accumulation of turf algae around the control ramets was conspicuous by Day 29, and this pattern persisted until the end of the trial (Fig. 1). In this experiment, observed algal turfs (examined macro- and microscopi- 
Table 1. Summary of water quality conditions during the $210 \mathrm{~d}$ trial. Data were collected hourly using a YSI multi-probe instrument. DO: dissolved oxygen; $\%$ sat.: percent oxygen saturation

\begin{tabular}{|lccccc|}
\hline Variable & $\mathrm{pH}$ & Temp. $\left({ }^{\circ} \mathrm{C}\right)$ & $\mathrm{DO}\left(\mathrm{mg} \mathrm{l}^{-1}\right)$ & $\mathrm{DO}(\%$ sat. $)$ & Salinity \\
\hline Average & 8.22 & 25.86 & 7.30 & 104.20 & 33.77 \\
SD & 0.14 & 0.36 & 0.51 & 3.07 & 2.33 \\
Minimum & 7.60 & 22.00 & 6.40 & 74.00 & 25.00 \\
Maximum & 8.53 & 26.60 & 10.21 & 109.00 & 37.40 \\
\hline
\end{tabular}

mortality occurred within the other 2 treatments. Repeated-measures analysis provided the following coral area change estimates (mean \pm SE growth rates) for the control, manually scraped and urchin-grazed treatments: $-0.78 \pm$ $0.29,3.08 \pm 0.29$ and $1.86 \pm 0.20 \mathrm{~mm}^{2}$ $\mathrm{d}^{-1}$, respectively (Fig. 2B). Post hoc $t$-tests indicated that the growth rates
Urchins

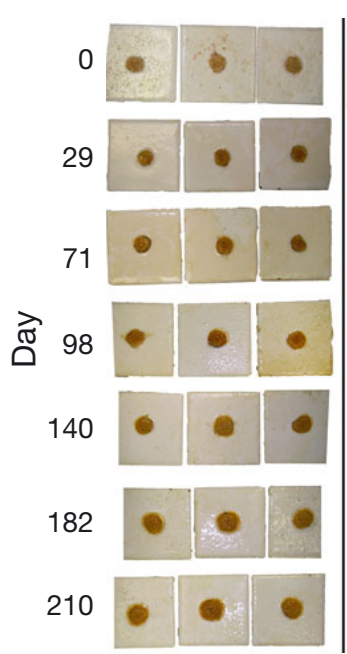

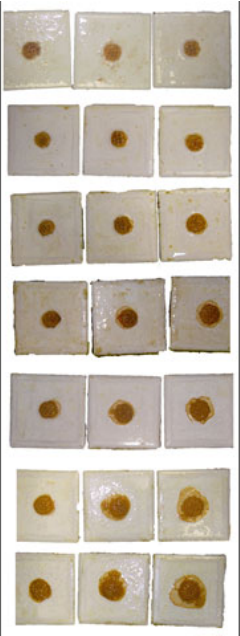

Scraped

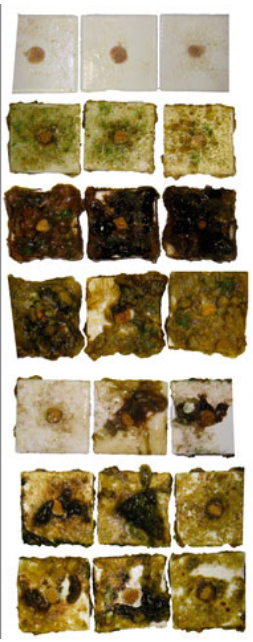

Control
Fig. 1. Acropora cervicornis. Examples of images from which ramet area measurements were obtained. Shown are examples of ramets under (A) urchin-removal (grazed), (B) manual-removal (scraped) and (C) control treatments. Images correspond (top to bottom) to Days 0 to 210 as labeled

cally) appeared to be predominantly composed of a diverse group of cyanobacteria, including the genera Lyngbya, Blenothrix, Phormidium, Schizothrix and Nodularia (L. Collado-Vides, Florida International University, pers. comm.). In contrast, development of algal turf around the urchin-grazed and manually scraped treatments was negligible from the first day of the trial to the last. Day 29 of the trial was also when mean ramet area trajectories of the manually scraped and urchin-grazed treatments diverged from the trajectory of the control (Fig. 2A). By the end of the trial, the mean area of coral ramets held with urchins ranged from 513 to $789 \mathrm{~mm}^{2}$, and those that had their substrates manually cleared of algal turfs (i.e. scraped) ranged from 761 to $1084 \mathrm{~mm}^{2}$. Area loss was evident among all control treatment replicates, with declines ranging from 12 to $233 \mathrm{~mm}^{2}$. By Day 210 , complete mortality of ramets within replicates in the control treatment was 0,66 and $66 \%$, whereas no
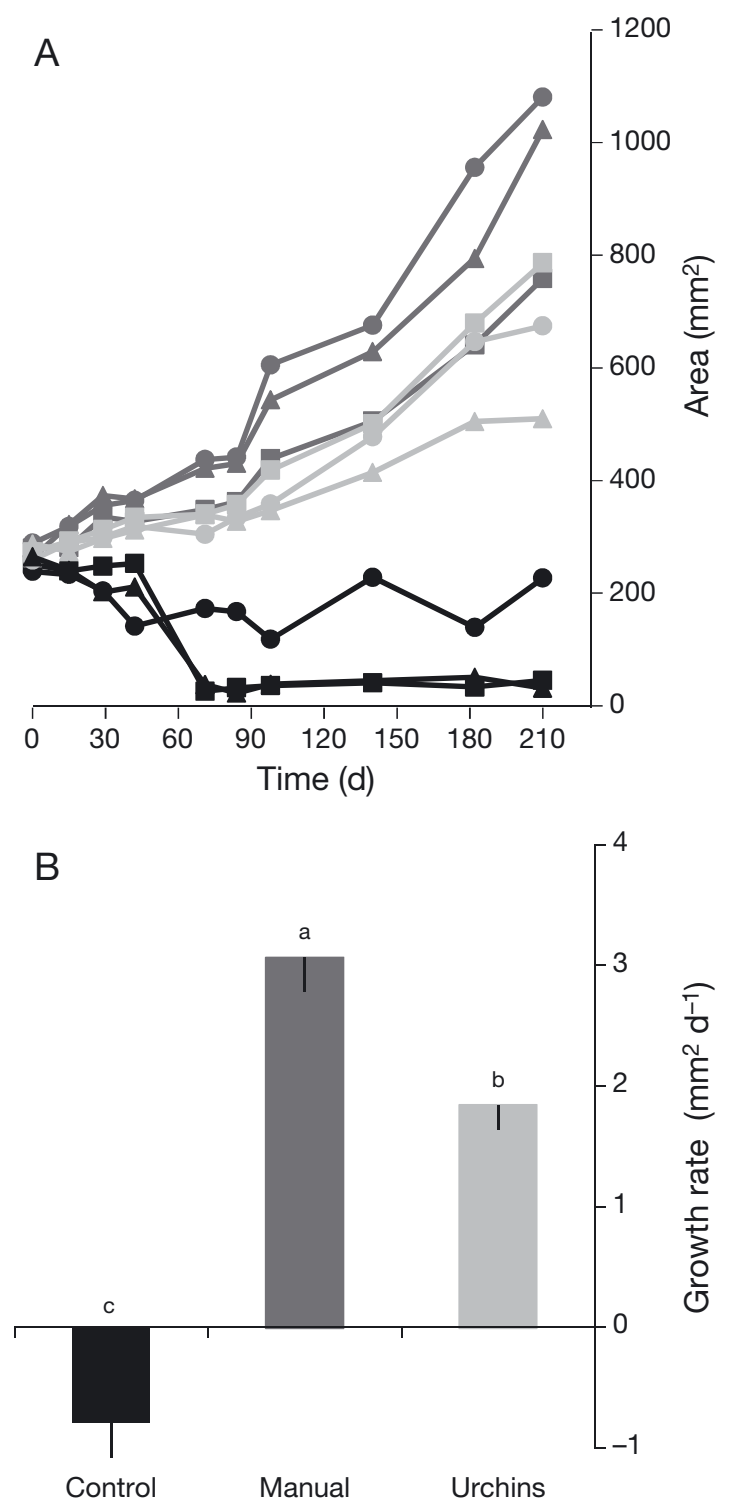

Fig. 2. Acropora cervicornis. (A) Ramet growth (for 3 replicates) under 3 laboratory treatments: (1) manual scraping of macrolagae (dark gray symbols and lines), (2) grazing by juvenile urchins (light gray) and (3) absence of both urchins and manual removal of macroalgae (black). (B) Comparison of ramet growth rates (lines indicate 1 standard error) for each treatment. Different lowercase letters indicate all rates are significantly different $(p<0.001)$ from one another 
of the manually scaped and urchin-grazed treatments differed significantly from the control $(p=0.003$ and $p=0.004$, respectively) and that the manually scraped treatment growth rate was significantly higher $(p=0.032)$ than the urchin-grazed treatment.

\section{DISCUSSION}

While the concept of laboratory bioassays using corals is not new, only recently have findings based on such studies appeared in the literature (e.g. Shafir et al. 2003, Bielmyer et al. 2010) and most still utilized field-harvested corals (e.g. Morgan \& Snell 2002, Renegar \& Riegl 2005, Markey et al. 2007), presenting the disadvantages of unknown ecological history and genotypic identity of the experimental subjects, as well as the depletion of wild populations. Supply of identical coral ramets of sufficient numbers and dimensions for laboratory experimentation requires coral culture systems that maintain high water quality and appropriate light conditions to minimize stress to each colony. Whereas water treatment and illumination systems are readily available from the aquarium industry, unwanted and costly competitors on coral substrates, which, if left unchecked, inhibit coral growth and survival, remain a pervasive problem (Lirman 2001, Yap \& Alvarez Molina 2003). Clearly, chemical application and/or light manipulation for reducing algal growth may have deleterious effects on the health of the corals and/or their symbionts (or otherwise compromise the coral assays for which they are intended). While mechanical (manual) removal of algae is a highly effective control option (Calfo 2007), it is a highly labor-intensive activity, especially when culturing 100 s to 1000 s of individual ramets (Forsman et al. 2006). Therefore, although coral growth in the presence of urchins is slower than with manual removal, human labor costs associated with the latter may out-weigh any production-rate improvements in large-scale (>700 ramet) operations (see cost comparisons in the Supplement at www.int-res. com/articles/suppl/n022p183_supp.pdf). Use of urchins to complement, not substitute for, manual scraping would provide ramet culturists with a degree of operational flexibility, especially if production targets change or labor problems emerge.

The ecological literature makes clear the paramount importance of grazing, especially by the longspined urchin Diadema antillarum in the Caribbean, in enhancing coral persistence and resilience (Sammarco 1980, Lessios 1988, Carpenter \& Edmunds
2006). However, there is growing recognition that grazers can also cause incidental mortality of the smallest corals (e.g. Okamoto et al. 2005, Baria et al. 2010); hence, grazing in the context of culturing small corals is a delicate balance to maintain control over competing algae without direct harm. For example, successful co-culture schemes of coral spat with grazing gastropods have proven successful off Okinawa (Omori 2005). Initial trials with laboratoryreared juvenile $D$. antillarum to control competition by macroalgae in coral culture efforts at our facility were unsuccessful, due to the propensity of these urchins to feed on coral tissue, as also reported under field conditions with high $D$. antillarum densities (Sammarco 1980).

Our results suggest that the use of cultured juvenile variegated sea urchins is an effective method of controlling algal turf overgrowth and enhancing coral growth of Acopora cervicornis within controlled environments without incurring the loss of coral tissue caused by the feeding action of more aggressive urchins. However, the use of Lytechinus variegatus to provide a substitute for labor-intensive manual control does come with some cost in terms of rate of coral production, requiring evaluation of the tradeoffs. Juvenile $L$. variegatus culture is a rapid (metamorphosis from the larval to the juvenile stage occurs in about $14 \mathrm{~d}$ ) and straightforward process as compared to other urchin species (George et al. 2004, Buitrago et al. 2005). Therefore, given the results of the present study and the relative ease of $L$. variegatus culture, we now routinely incorporate $L$. variegatus in the coral ramet production process.

Research is necessary to evaluate the potential role of small herbivores such as Lytechinus variegatus for enhancing post-settlement coral survival and growth under field conditions. Moreover, ready access to genetically identical coral ramets of consistent size, morphology, environmental history and condition is essential for laboratory studies designed to examine coral disease, toxicology and physiology, including investigation of the effects of changing ocean temperature and $\mathrm{pH}$ on corals and their symbionts. The model culture system involving propagation of small fragments of coral tissue and co-culture of juvenile $L$. variegatus holds promise for meeting the growing needs of the research community for experimental coral material. The present study, therefore, points to an effective, supplementary tool for tackling the algal competition problem - one of the several important, labor-intensive challenges involved in maintaining large numbers of sensitive, slowgrowing corals in the laboratory. 
Acknowledgements. Funds for this study were provided by the National Park Service and the Herbert W. Hoover Foundation (Canton, Ohio). Coral source material was collected under Florida Fish and Wildlife Commission Permit SAL05SRP-948. We are indebted to A. Boyd, D. Stommes, N. Frisbe and L. Collado-Vides for their technical assistance.

\section{LITERATURE CITED}

Alvarez-Filip L, Dulvy NK, Gill JA, Côte IM, Watkinson AR (2009) Flattening of Caribbean coral reefs: region-wide declines in architectural complexity. Proc R Soc Lond B Biol Sci 276:3019-3025

Baria MVB, Guest JR, Edwards AJ, Aliño PM, Heyward AJ, Gomez ED (2010) Caging enhances post-settlement survival of juveniles of the scleractinian coral Acropora tenuis. J Exp Mar Biol Ecol 394:149-153

Barott KL, Williams GJ, Vermeij MJA, Harris J, Smith JE, Rohwer FL, Sandin SA (2012) Natural history of coral-algae competition across a gradient of human activity in the Line Islands. Mar Ecol Prog Ser 460: $1-12$

Bielmyer GK, Grosell M, Bhagooli R, Baker AC, Langdon C, Gillette P, Capo TR (2010) Differential effects of copper on three species of scleractinian corals and their algal symbionts (Symbiodinium spp.). Aquat Toxicol 97: 125-133

Birrell CL, McCook LJ, Willis BL, Diaz-Pulido G (2008) Effects of benthic algae on the replenishment of corals and the implications for the resilience of coral reefs. Oceanogr Mar Biol Annu Rev 46:25-64

> Buitrago E, Lodeiros C, Lunar K, Alvarado D and others (2005) Mass production of competent larvae of the sea urchin Lytechinus variegatus (Echinodermata: Echinoidea). Aquacult Int 13:359-367

Calfo A (2007) Book of coral propagation: reef gardening for aquarists. Reading Trees Publications, Monroeville, PA

Capo TR, Jaramillo JC, Boyd AE, Lapointe BE, Serafy JE (1999) Sustained high yields of Gracilaria (Rhodophyta) grown in intensive large-scale culture. J Appl Phycol 11: 143-147

> Capo TR, Bardales AT, Gillette PR, Lara MR, Schmale MC, Serafy JE (2009) Larval growth, development, and survival of laboratory-reared Aplysia californica: effects of diet and veliger density. Comp Biochem Physiol C 149: 215-223

> Carpenter RC, Edmunds PJ (2006) Local and regional scale recovery of Diadema promotes recruitment of scleractinian corals. Ecol Lett 9:271-280

> Diaz-Pulido G, McCook LJ (2004) Effects of live coral, epilithic algal communities and substrate type on algal recruitment. Coral Reefs 23:225-233

> Diaz-Pulido G, McCook LJ, Dove S, Berkelmans R and others (2009) Doom and boom on a resilient reef: climate change, algal overgrowth and coral recovery. PLoS ONE 4:e5239

> Forsman ZH, Rinkevich B, Hunter CL (2006) Investigating fragment size for culturing reef-building corals (Porites lobata and $P$. compressa) in ex situ nurseries. Aquaculture 261:89-97

Gardner TA, Côte IM, Gill JA, Grant A, Watkinson AR (2003) Long-term region-wide declines in Caribbean corals. Science 301:958-960

George SB, Lawrence JM, Lawrence AL (2004) Complete larval development of the sea urchin Lytechinus variegatus fed an artificial feed. Aquaculture 242:217-228

Hughes TP, Baird AH, Bellwood DR, Card M and others (2003) Climate change, human impacts, and the resilience of coral reefs. Science 301:929-933

Hughes TP, Bellwood DR, Folke CS, McCook LJ, Pandolfi JM (2007) No-take areas, herbivory and coral reef resilience. Trends Ecol Evol 22:1-3

> Hurlbert SH (1984) Pseudoreplication and the design of ecological field experiments. Ecol Monogr 54:187-211

Lessios HA (1988) Mass mortality of Diadema antillarum in the Caribbean: What have we learned? Annu Rev Ecol Syst 19:371-393

> Lirman D (2001) Competition between macroalgae and corals: effects of herbivore exclusion and increased algal biomass on coral survivorship and growth. Coral Reefs 19:392-399

> Markey KL, Baird AH, Humphrey C, Negri AP (2007) Insecticides and a fungicide affect multiple coral life stages. Mar Ecol Prog Ser 330:127-137

Mayer AG (1914) The effects of temperature upon tropical marine animals. Pap Tortugas Lab Carnegie Inst Wash 6: $1-24$

McCook LJ, Jompa J, Diaz-Pulido G (2001) Competition between corals and algae on coral reefs: a review of evidence and mechanisms. Coral Reefs 19:400-417

- Miller J, Muller E, Rogers C, Waara R and others (2009) Coral disease following massive bleaching in 2005 causes $60 \%$ decline in coral cover on reefs in the US Virgin Islands. Coral Reefs 28:925-937

Morgan MB, Snell TW (2002) Characterizing stress gene expression in reef-building corals exposed to the mosquitocide dibrom. Mar Pollut Bull 44:1206-1218

Mumby PJ, Steneck RS (2008) Coral reef management and conservation in light of rapidly evolving ecological paradigms. Trends Ecol Evol 23:555-563

Mumby PJ, Harborne AR, Williams J, Kappel CV and others (2007) Trophic cascade facilitates coral recruitment in a marine reserve. Proc Natl Acad Sci USA 104:8362-8367

Okamoto M, Nojima S, Furushima Y, Phoel WC (2005) A basic experiment of coral culture using sexual reproduction in the open sea. Fish Sci 71:263-270

$>$ Omori M (2005) Success of mass culture of Acropora corals from egg to colony in open water. Coral Reefs 24:563

> Omori M, Kubo H, Kajiwara K, Matsumoto H, Watanuki A (2006) Rapid recruitment of corals on top shell snail aquaculture structures. Coral Reefs 25:280

> Paddack MJ, Reynolds JD, Aguilar C, Appeldoorn RS and others (2009) Recent region-wide declines in Caribbean reef fish abundance. Curr Biol 19:590-595

Renegar DA, Riegl BM (2005) Effect of nutrient enrichment and elevated $\mathrm{CO}_{2}$ partial pressure on growth rate of Atlantic scleractinian coral Acropora cervicornis. Mar Ecol Prog Ser 293:69-76

Riebesell U, Fabry VJ, Hansson L, Gattuso JP (2010) Guide to best practices in ocean acidification research and data reporting. European Project on Ocean Acidification. Available at www.epoca-project.eu/index.php/Home/ Guide-to-OA-Research/ (accessed 11 November 2013)

> Rinkevich B, Shafir S (1998) Ex-situ culture of colonial marine ornamental invertebrates: concepts for domestication. Aquarium Sci Conserv 2:237-250

Sammarco PW (1980) Diadema and its relationship to coral spat mortality: grazing, competition, and biological disturbance. J Exp Mar Biol Ecol 45:245-272 
SAS (1990) SAS/STAT user's guide, Version 6. SAS Institute, Cary, NC

Shafir S, Van Rjin J, Rinkevich B (2003) The use of coral nubbins in coral reef ecotoxicology testing. Biomol Eng 20:401-406

Shafir S, Van Rijn J, Rinkevich B (2006) Coral nubbins as source material for coral biological research: a prospectus. Aquaculture 259:444-448

Villanueva RC, Edwards AJ, Bell JD (2010) Enhancement of grazing gastropod populations as a coral reef redtoration tool: predation effects and related applied implications. Restor Ecol 18:803-809

Editorial responsibility: Paul Snelgrove, St. John's, Newfoundland and Labrador, Canada
Wilson SK, Graham NAJ, Fisher R, Robinson J and others (2012) Effect of macroalgal expansion and marine protected areas on coral recovery following a climatic disturbance. Conserv Biol 26:995-1004

Woodley CM, Bruckne AW, Galloway SB, McLaughlin SM and others (2003) Coral disease and health: a national research plan. National Oceanic and Atmospheric Administration, Silver Spring, MD

Yap HT, Alvarez Molina R (2003) Comparison of coral growth and survival under enclosed, semi-natural conditions and in the field. Mar Pollut Bull 46:858-864

Submitted: March 8, 2013; Accepted: September 6, 2013

Proofs received from author(s): November 14, 2013 